Revista de la red interuniversitaria de estudios sobre las literaturas rioplatenses contemporáneas en Francia

$10 \mid 2014$

El XIX en el XX

\title{
Versiones de Ansina en la ficción uruguaya contemporánea (1993-2001)
}

\section{Alejandro Gortázar}

\section{OpenEdition}

\section{Journals}

Edición electrónica

URL: http://journals.openedition.org/lirico/1706

DOI: 10.4000/lirico.1706

ISSN: 2262-8339

Editor

Réseau interuniversitaire d'étude des littératures contemporaines du Río de la Plata

\section{Referencia electrónica}

Alejandro Gortázar, « Versiones de Ansina en la ficción uruguaya contemporánea (1993-2001)»

Cuadernos LIRICO [En línea], 10 | 2014, Puesto en línea el 01 marzo 2014, consultado el 02 mayo 2019. URL : http://journals.openedition.org/lirico/1706 ; DOI : 10.4000/lirico.1706

Este documento fue generado automáticamente el 2 mayo 2019.

\section{cc) $(7)$}

Cuadernos LIRICO está distribuido bajo una Licencia Creative Commons Atribución-NoComercialSinDerivar 4.0 Internacional. 


\title{
Versiones de Ansina en la ficción uruguaya contemporánea (1993-2001)
}

\author{
Alejandro Gortázar
}

\section{Introducción}

1 En la segunda mitad de la década de los noventa Hugo Verani (1996), Óscar Brando (1997) y Hugo Achugar (1998) confirmaban en sus trabajos dos tendencias editoriales dominantes en la literatura uruguaya entre 1985 y1995: la novela histórica y el testimonio. Los tres investigadores coinciden en la importancia de la dictadura cívicomilitar y el proceso posdictatorial como condición para la emergencia de estos géneros. Algunos agregan a estos elementos locales, la posmodernidad y la crisis de los metarrelatos (Lyotard) como marco global y proceso civilizatorio. Para el caso de la novela histórica, además de estos elementos, se agregan la interpelación a una idea de la "identidad nacional" excluyente y un fuerte cuestionamiento a las narrativas oficiales que intentan restaurar una identidad nacional previa a la dictadura. En ese proceso la Historia como disciplina, y la Historia Nacional como discurso, son fuertemente interpeladas por la ficción dando como resultado distintas respuestas estéticas al problema de narrar la nación.

2 En De la vanguardia a la posmodernidad : narrativa uruguaya (1920-1995) Verani coloca el tema en el eje modernidad/posmodernidad : mientras la modernidad destaca la originalidad de la obra -afirma- la postmodernidad postula la re-escritura de "materiales preexistentes" (45) y el uso de "los vacíos de la historia como pretexto para la libertad inventiva". Esta condición postmoderna es la que alienta una "nueva modalidad narrativa" que implica : “(...) la revisión crítico-imaginativa de la historia [...] o, más específicamente, el interés por la «metaficción historiográfica » (...) [m]ediante la parodia, la nueva novela histórica problematiza y subvierte los propósitos de veracidad y objetividad, las perspectivas autoritarias que mueven a la modalidad tradicional (46). 
3 Por su parte, Oscar Brando (1997) señala la publicación de la novela Bernabé, Bernabé de Tomás de Mattos en 1988 como un hito central para la comprensión de la nueva novela histórica, que tiene como "tema predominante" la violencia y como ámbito principal el siglo XIX. Para el caso de Bernabé, Bernabé, la muerte de Bernabé Rivera y el intento de eliminar a los indígenas en Uruguay. Para Brando el género no rindió culto a la épica sino que narró "las fisuras de un conglomerado social que se postuló como integrador", volviéndose en algunos casos una anti-épica (23). Para Achugar (1998), como para Brando, la dictadura deterioró "el imaginario tradicional de la sociedad uruguaya", dando paso en la postdictadura a una revisión de "las claves tanto del pasado como de una identidad nacional en crisis o en proceso de transformación” (233). La gran mayoría de los escritores profesionales uruguayos, como muchos de sus pares latinoamericanos desde fines de los setentas, no retomaron ni el género ni el proyecto ideológico de la novela histórica decimonónica, sino que promovieron su carnavalización, su parodia e incluso su desintegración. Desde la mitad de la década de los noventas hasta el presente las dos líneas mencionadas por los críticos han continuado. En este trabajo analizo dos novelas que se publican en el período y el marco interpretativo planteado por los críticos: Memorias de Ansina (1994) de Diego Bracco y Artigas Blues Band (1994) de Amir Hamed. La primera, escrita por un profesor de historia, ensayista e investigador, es decir, un escritor amateur poco conocido en el campo literario, es la más fácil de ubicar en la serie "nueva novela histórica". Sin embargo la segunda presenta problemas y hasta es posible plantear que está escrita contra el fenómeno editorial. ${ }^{1}$ La tercera novela es La soledad del General (2001) de Jorge Chagas, la primera novela de un escritor afrodescendiente que inicia su trayectoria profesional en la literatura. Las tres novelas abordan la historia-mito de Ansina desde estéticas distintas y proponen interpretaciones que innovan, dialogan o discuten las distintas versiones oficiales.

\section{Ansina : la historia oficial}

Desde la mención de un tal Lenzina publicada en un periódico de Montevideo en 1846 hasta la actualidad Ansina fue objeto de múltiples disputas que resumiré en cuatro hitos. ${ }^{2}$ El primero es el origen de Ansina. El ensayo Vida del Brigadier General D. José Gervasio Artigas, fundador de la nacionalidad oriental (1860) de Isidoro de María, la primera obra de largo aliento sobre Artigas, ficcionaliza el día exacto en que el héroe decide pedir asilo al dictador Francia en Paraguay :

Una noche rodeado de sus más leales y constantes compañeros, les revela su última y heroica resolución, -pedir al Paraguay un asilo, dando un adiós a la Patria. Ansina, su buen Ansina, es el primero que puesto en pie le responde - "mi General, yo lo seguiré aunque sea hasta el fin del mundo" (32)

5 La frase final sirivió de fuente para que en el siglo XIX la sensibilidad romántica reescribiera este episodio. Hay al menos dos ejemplos de esto en un texto de Timoteo (Washington P. Bermúdez) contenido en su Baturrillo uruguayo (1885) y en el poema "La muerte de Artigas" (1891) de Manuel Bernárdez. Se sella así una primera representación del buen Ansina, fiel al buen Artigas, es decir, la historia del buen amo y el buen esclavo.

6 El segundo hito fue la repatriación de los restos de Manuel Antonio Ledesma y su posterior colocación en el Panteón Nacional, liderada en 1936 por el inspector del Ejército Mario Petillo. Petillo aseguraba, pese a la resistencia del Insituto Histórico y Geográfico, que los restos de Ledesma eran los restos de Ansina y debían ser repatriados con el fin de 
fijar la conmemoración del "Día del Soldado". Ledesma, convertido en Ansina, era el símbolo de la subordinación de los soldados de tropa al superior y también de la subordinación de toda una "raza" :

La raza de color que habita desde tiempos lejanos en estas regiones rioplatenses, fué, en las luchas del pasado factor preponderante de victoria. Dicha raza contó con el hombre que motiva esta obra, hombre cuyo espíritu se exalta en estas páginas, como un motivo patriótico de homenajear a esa raza, digna por todo concepto de la más alta consideración

$(\mathrm{s} / \mathrm{p})$

7 Este hito no es nada menor dado que consolida un tercero : la inauguración de la estatua a Ledesma-Ansina en Montevideo. El Estado resolvió a favor de utilizar el nombre de Ledesma y durante décadas el monumento tuvo grabado ese nombre en la piedra. La estatua, creada por el escultor José Belloni (1862-1965), es descrita en Estatuas y monumentos de Montevideo (1976) como una figura sedente (Ansina) al frente de una reproducción del cuadro "Artigas en la Ciudadela", encargado al pintor Juan Manuel Blanes (1830-1901) por la "Cámara de Senadores" en 1885, en el que el General está parado. La representación de un Ansina subordinado, sentado pero al mismo tiempo representado a un soldado criollo, vestido con "poncho patrio", "botas de potro" y "lanza de tacuara" (21). ${ }^{3}$ Con este tercer hito la imagen de un Ansina sumiso, bueno, dócil se consolida en la conciencia letrada. Esta representación, que comenzó a configurarse en la segunda mitad del siglo XIX, fue recogida y reproducida por el Estado en la educación, en monumentos, imágenes y textos durante el siglo XX.

8 Pero en 1951, apenas pasada la fiebre de homenajes al centenario de la muerte de Artigas, Daniel Hammerly Dupuy y Victor Hammerly Peverini hicieron circular una nueva versión de Ansina que ponía en entredicho la historia oficial. Los autores publicaron en Buenos Aires dos volúmenes de poesía dedicada a Artigas por diversos autores latinoamericanos, en la que incluyen un conjunto importante de textos atribuidos a Joaquín Lenzina, al que plantean como el verdadero Ansina. La novedad era doble: Manuel Antonio Ledesma no era Ansina y además el asistente era en verdad un "fiel payador de Artigas". La nueva versión seguía recurriendo a la fidelidad pero al mismo tiempo le daba a Ansina una voz e incluso una letra. Pero había un problema que los investigadores consignan en un texto explicativo : los originales de los poemas de Ansina se perdieron en Paraguay. La única prueba de su existencia es la palabra de los antólogos. El episodio agregaba más confusión a la ya enredada historia de Ansina. Sin embargo, la novedad no movilizó la conciencia letrada de la época, con excepción de Ildefonso Pereda Valdés, quien le dedica algunas palabras en un folleto (1964: 16) para desestimarlos.

9 En la postdictadura la historia-mito de Ansina fue reescrita y reinterpretada en el marco de los debates sobre la "identidad nacional" en el campo intelectual y las fuertes críticas a la narrativa fundacional del Estado-nación por parte del movimiento social negro. Pero las explicaciones que ataban las novelas históricas al contexto del fin de siglo XX apenas percibieron el inicio de un proceso que continúa hasta el presente. Las novelas de Bracco, Hamed y Chagas, desde posiciones y estéticas distintas, participan en un reajuste de la narrativa del Estado-nación pero en un diálogo abierto con todas las versiones de Ansina, oficiales y no oficiales, historiográficas y políticas. 


\section{Fin de siglo}

10 En 1994 la editorial Fin de siglo publica las novelas de Hamed y Bracco, que en rigor había sido publicada por el autor en 1993. Dos novelas muy distintas en su estructura, en su estética y también en las repercusiones locales e internacionales. Memorias de Ansina simula una autobiografía con un capítulo introductorio (I) y un relato entre los capítulos II y XXII -es decir, la casi totalidad del texto- en la que Ansina cuenta su vida hasta 1812. El autor ficcionaliza la voz de Ansina a partir de distintos documentos que le permiten contar todas las historias contenidas en la novela. Sin embargo, las dos intervenciones que enmarcan el relato -Prólogo y Nota final- le aportan un tono irónico que busca romper el "pacto de lectura" autobiográfico y desestabiliza la historia narrada. El texto de Bracco no tuvo mayores repercusiones en la crítica local, de hecho ninguno de los tres críticos lo incluye en la lista de novelas históricas del período, ni tampoco repercusiones internacionales.

11 La novela de Hamed irrumpe en el medio local y se proyecta internacionalmente por plantear una estética heredera de "un barroco latinoamericano" (Basile, $2005: 52)$, un discurso polifónico que desborda el relato. No se pretende reconstruir un pasado sino dinamitar la historia mediante un procedimiento poco convencional desde la perspectiva de la nueva novela histórica local: Artigas renace de sus cenizas en el mausoleo que la dictadura le ha construido. Lo acompaña, como un fanstama, su fiel asistente Ansina. El asunto se resuelve con una estructura narrativa explícitamente fragmentaria, sin orden cronológico -empieza en el capítulo 6 y termina en el 1- y plagada de citas explícitas e implícitas a distintos autores. La novela propone un desafío para cualquier lector convencional. Como sostiene Teresa Basile :

La textualidad de Artigas Blues Band es un continuum de la escritura que fluye y en su fluencia mezcla las voces narradoras de sus personajes, transita por la contigüidad de los espacios, se desplaza comadamente por los tiempos diversos, abre pasajes entre la vigilia, el sueño, la literatura, desarma las matrices genéricas. Y es el humor el que muchas veces diluye las fronteras entre diversos tonos del discurso, relee la tragedia en clave cómica, la épica como chifladura (57)

12 La novela de Hamed fue, según Verdesio, poco entendida por el establishment cultural local (2004: 308), aunque su obra es bien conocida y estudiada por académicos en el resto del mundo. Tal vez el humor desacralizador con el que enfrentó "lo nacional" explique la incomprensión de la crítica literaria y cultural local.

13 El caso de Memorias de Ansina se acerca al modelo de Bernabé, Bernabé de Tomás de Mattos porque produce el simulacro de unas "memorias" escritas por Ansina, que llegan por accidente a quien escribe el prólogo. En Bernabé, Bernabé un tal M.M.R. firma un texto fechado en Tacuarembó el 12 de octubre de 1946 que sirve de presentación a un manuscrito fechado en 1885 y firmado por Josefina Péguy, un personaje ficiticio que relata la historia de Bernabé Rivera durante la campaña de exterminio de los charrúas en 1832. Aunque el punto de partida es parecido, Bracco trabaja este mismo simulacro en otro sentido. A diferencia de M.M.R. el Profesor Bracco, quien firma el "Prólogo" y supongo autor de la "Nota final", se introduce en el relato a través de unas notas a pie en las que aclara términos de época o menciona documentos que confirman los hechos narrados. En el "Prólogo", por ejemplo, además de relatar la forma en que tomó contacto con los "manuscritos" de Ansina el Profesor Bracco adelanta que tiene "tan pocas dudas 
de la autenticidad del manuscrito que se transcribe a continuación, como de la existencia misma del fiel ayudante del General Artigas". La ironía se refuerza en la "Nota final" con la puesta en duda de la existencia misma de Ansina y con una serie de aclaraciones sobre la manipulación de los documentos peresentados durante el relato.

14 Estos dos textos descolocan al lector y le dan al personaje histórico un carácter ficcional. La parodia del historiador, la presencia del aparato erudito en las notas a pie (casi todas provienen de distintos tomos del Archivo Artigas), impulsan el relato, la verosimilitud de la voz autobiográfica. $\mathrm{El}$ artefacto creado por Bracco necesita el discurso historiográfico para hacer posible el relato y se mueve dentro de las coordenadas establecidas por ese discurso. En Artigas Blues Band el tratamiento de la Historia como disciplina es distinto, en parte opuesto al de Bracco. Según Verdesio (1996) la novela "no propone la historia como documento legitimador (...) sino como algo construido (como constructo o artefacto) y, por lo tanto, como algo a deconstuir [son] sometidos a una lectura en tanto que monumentos y no en tanto documentos" (46). Por ejemplo, las citas a cartas y documentos de Artigas y de otros "grandes hombres" son explícitamente desconstextualizadas.

15 Pero el elemento más distorcionante es la carnavalización: el "uso sostenido y estructurante del humor" (45) no solamente desacraliza la historia oficial sino, como plantea Verdesio, es un "recurso estilístico para descolocar e inquietar al lector" (46). Tal vez el discurso de Ariel sobre Artigas sea el que represente mejor esta idea :

(...) A cagar, caballeros. La historia de este abrsurdo país está conformada de ideas socialdemócratas. Nos han legado una mentira tremebunda. Que el líder de unos gauchos y de unos indios feroces como hienas fuera un benefactor, un hombre piadoso (...) y toda la centuria disfrutamos de una historia de comemierdas por la que el prócer en nada se distingue del gran socialdemócrata de José Batlle, el que inventó el país al siglo siguiente, o de José Varela, el que lo educó. (se agitaba en el asiento) Pero ustedes, babafías, me hablarán de un prócer protomarxista (...) el gran Artigas fue un protohéroe, pertenece a nuestra edad de bronce, c'est tout. Protouruguayo prepartidario y férreo, hombre meritorísimo pero jamás un santo (...) Fuck you, ladies and gentlemen, hicieron un héroe de relaciones públicas (257-258)

16 Pero este aspecto disolvente del discurso de Ariel no es la única forma de contestar la historia oficial sobre Artigas. La propia invención de la llegada de Artigas al presente, como una especie de ave fénix, desafía el discurso de la Historia. Algo similar ocurre cuando Artigas constata con cierto pesar que es el autor de la identidad uruguaya. En ese marco Ansina es presentado como un fantasma que merodea en los alrededores de la tumba de Articas desde la llegada de los restos de Artigas a Montevideo. Por esa razón Ansina lo ha visto todo, sabe más del Artigas fundador que el propio Artigas y lo orienta en sus primeros pasos luego de renacer.

17 En Artigas Blues Band todas las representaciones disponibles sobre Ansina aparecen mezcladas: es el "fiel escudero" (Manuel Antonio Ledesma) y también el cantor (el Joaquín Lenzina de Hummerly). A su vez la relación Artigas-Ansina es proyectada en las relaciones de Ariel con los personajes : con Gustavo (su amigo), con Susana (su pareja), a quienes les pide que le digan "Mi general" y son llamados "Ansina". El recurso del humor también desestabiliza e invierte la relación de subordinación al presentar a Ansina como el que sabe, mientras Artigas no entiende nada. Sin embargo, la opción por el Ansina guitarrero y cantor es la más interesante de la novela. Hamed no pudo tomarla de otro lugar que no fuera la antología de Hummery de 1951. 
18 En uno de los fragmentos del capítulo “Tres”, escrito en estilo indirecto libre, el narrador propone a un Ansina cantando un blues, "los tres tonos sureños de ese país enorme del que tanto había siempre hablado el general” (202). Ansina se salta así el tiempo histórico y se pregunta “(...) Por qué no, tan simple que es. Y pocas veces se había sentido tan entero cantando algo como entonces, donde no sabía qué cantar, ni ya dónde estaba" (202). Las guitarreadas con los gauchos ya no le sirven, aunque el blues contiene algo familiar: "Los blues se cortan o se se siguen sin fin. Son como payar a solas. Con uno mismo" (202). Ansina está solo, no dialoga con Artigas, y quisiera que "lo reclamen una vez más, juglar, venga y cante, la paisanada (dónde estarán nuestros hombres en este presente espectral) anda gustosa de oírlo, tal vez todos se reúnan una vez más para que él les cante, les diga una vez más mi madre me llamaba Joaquín, como me había puesto mi amo, pero que de donde viene lo llaman Ansina, y que él siempre tuvo en alto honor de llamarse a sí mismo la sombra de Artigas" (203). El narrador copia y resume varios versos de Joaquín Lenzina en la novela y esto no solamente impugna el relato oficial sino que, sobre todo en este capítulo, plantea un Ansina distinto al soldado criollo del monumento. El Ansina de Artigas Blues Band además de invertir la relación tradicional de servidumbre con Artigas, dialoga con el blues a través de sus payadas y se conecta con un estilo musical, globalizado por el rock, producto de la diáspora africana en todas las Américas.

19 La novela de Bracco consiste en el simulacro de unas "memorias" escritas por Ansina comentadas por un "Profesor Diego Bracco", que de un modo irónico duda de la existencia de alguien llamado Ansina. De hecho lo nombra "Juan Núñez" y reconoce en la "Nota final" que todos los nombres de los documentos citados fueron modificados por él (2004 : 129). El Ansina de Bracco no es ni Ledesma ni Lenzina y su historia difiere de las historias asociadas a ambos nombres. Es un Ansina letrado, que aprendió a leer y a escribir con los padres franciscanos en Tucumán, y que ve en retrospectiva su vida y la relata con el "General" como centro. De hecho la novela se inicia relatando su encuentro con Artigas, el día mismo que se ganó su confianza por una acción heroica, a diferencia del relato tradicional que ubica a Ansina el día en que el héroe decide exilarse en Paraguay y le declara que lo seguirá “aunque sea hasta el fin del mundo". De hecho las memorias de Ansina no mencionan ese episodio porque se agotan en 1812.

20 El relato de Bracco presenta un Ansina que fue un esclavo fiel a un amo blanco (Capítulo $\mathrm{V})$, que consiguió la libertad por sus acciones y permaneció fiel a su amo aún siendo libre (Capítulo VIII). Cuando narra el día que Artigas le perdona la vida (Capítulo XV) Ansina afirma que pasó “a formar parte del grupo cercano al General, que me honró el resto de su vida con la más completa confianza" (85) y aunque nada disminuye su admiración por él recuerda con amargura "que, el mejor hombre, el mejor hermano, en un tiempo en que hasta los ingleses trabajaban contra la esclavitud, no se haya atrevido a ser el principal en la causa de la abolición" (85). Si bien Ansina recuerda a su superior con admiración también le reprocha, como descendiente de africano, su ambigüedad frente a la esclavitud. En otro pasaje cuando escapa de la Montevideo sitiada, Ansina relata las tareas que cumplía para Artigas en Montevideo (Capítulo XXI) : “de inmediato me presenté ante el General a quien di cuenta de mis actividades en la plaza -de las que estaba bien informado- y de las noticias que había tenido acerca de un plan de los de Buenos Aires para asesinarlo" (123). A diferencia de Hamed, Bracco no utiliza los materiales disponibles sobre Ansina, confirmados o no por la Historia, aunque podemos presuponer que el Profesor los conoce por sus comentarios al inicio y cierre de la novela. La novela de Bracco presenta un Ansina verosimil cuya historia es en verdad tomada de diferentes 
documentos de época, y aún así ese Ansina verosimil se desvía de la historia oficial, presentándonos a un espía, un hombre de confianza de Artigas, que incluso señala en sus memorias las contradicciones del héroe.

21 El contexto de la posdictadura, como señala Verdesio, fue un "elemento significativo" (42) para explicar la nueva novela histórica en Uruguay. Lo que estas dos novelas hicieron, junto a otras, fue someter a juicio "los mitos anteriores" a la dictadura, al mismo tiempo que pusieron en circulación memorias alternativas, como la de Ansina, para mostrar lo inútil que resulta "imponer una memoria colectiva, una historia oficial única e indivisible" que los ritos del Estado contribuyen a consolidar (42). Si bien hay diferencias sustanciales en la apuesta estética : la novela de Bracco es tímida, aunque irónica, la de Hamed es osada e irrespetuosa con la Historia y asume con comodidad la narración del mito; ambas novelas discuten los relatos oficiales y generan las condiciones de posibilidad para resituar a Ansina en la conciencia letrada.

\section{Un nuevo relato}

Dos años después de la publicación de las novelas de Bracco y Hamed un colectivo de investigadores asociados a Organizaciones Mundo Afro publica Ansina me llaman y Ansina yo soy. ${ }^{4} \mathrm{El}$ procedimiento es sencillo: separan los supuestos textos de Ansina de la antología publicada en 1951 y los publican con algunos estudios preliminares. Los ensayos insisten en presentar a Joaquín Lenzina como el verdadero Ansina, negado por la historia oficial. Este relato contrahegemónico tiene el mismo efecto desestructurante de la historia oficial que pudo tener Artigas Blues Band pero, a diferencia de la novela, postula una verdad histórica que, indirectamente, le niega validez al mito y refuerza la historia como relato legítimo.

23 Casi al mismo tiempo y también en 1996 una banda de rock -Cuarteto de nos- edita el disco El tren bala (1996) que contiene la canción "El día que Artigas se emborrachó". El tema desató una polémica que tuvo como resultado que el disco se vendiera exclusivamente a mayores de 18 años. En la canción un Artigas muy borracho confunde a Ansina con una mujer, lo que provocó la reacción inmediata de Organizaciones Mundo Afro, que en ese momento publicaba el libro con los poemas de Ansina. En el debate intervinieron periodistas, historiadores, militares y políticos. Fue el debate entre tan diversos actores lo que animó a Jorge Chagas, novelista y periodista afrodescendiente, a escribir La soledad del General (2001) prolongando así en el siglo XXI los ecos de esta historia del siglo XIX.

24 En julio de 2012 entrevisté a Jorge Chagas y le pregunté cómo se le había ocurrido la novela. Su respuesta fue :

(...) Tomás Lihn desde [el semanario] Búsqueda salió a defender al Cuarteto de Nos diciendo una cosa muy interesante "En Estados Unidos no tienen problema con Washington (...) se burlan de ellos, usan camisetas de ellos, no son vacas sagradas, son los padres fundadores pero...no es una cosa intocable." (...) Ese artículo le provocó a Tomás que hubiera en "Carta a los lectores" de Búsqueda un ataque. Yo salí a defenderlo. Me pelié con Pelfort ${ }^{5}$, después nos hicimos amigos, como fue una discusión con altura. Perlfort siempre respetó eso. A raíz de eso se me ocurrió, vamos a hacer un Artigas más humano, fuera del bronce. Ese fue el nacimiento de L a soledad del general. ${ }^{6}$ 
Como en Artigas Blues Band la novela de Chagas presupone los discursos de la Historia y también las monumentalizaciones del Estado. A partir de ellas se propone escribir otro Artigas. La soledad del General no asume la tarea de reconstruir un contexto y hacer creíble un Ansina como Memorias de Ansina, ni repite la apuesta riesgosa, por barroca y carnavalizante, de Artigas Blues Band. Sin embargo Chagas se acerca al discurso de Bracco en la medida en que Ansina tiene una presencia fantasmática en su texto -Artigas, en su delirio, lo llama en casi todos los capítulos y Ansina no lo obedece- como si nunca hubiera exisitido, que es lo que irónicamente propone Memorias de Ansina. Por otro lado, la novela compuesta de fragmentos breves de Chagas introduce una línea lírica y mágica, emparentada con su modelo -Yo, el supremo (1974) de Augusto Roa Bastos-, que domina su lectura de los relatos historiográficos y políticos sobre Artigas. Esta opción, que Hamed explora desde una estética distinta, tiene el mismo resultado: desestabilizar la figura heroica de Artigas mediante su desacralización.

26 En este marco interpretativo La soledad del General contesta la representación oficial y pone en escena un nuevo Ansina. En el segundo fragmento de la novela Artigas, delirando de fiebre, llama al "único sirviente negro que me ha quedado" (27). A lo que Ansina responde:

No, General. No. No. Yo soy su último soldado-poeta y payador. El único y el último. Nuestra gran Provincia Oriental / proclama al mundo su fuero / Bandera de los pueblos libres/con esta noche / y tu rojo en el mar. ¡Cómo le agradaba esa estrofa, General! Apaciguaba sus furias, adormecía su espíritu bagualón, sosegaba sus cóleras, sus desconfianzas. Mis versos eran un arrullo que lo volvían morrongo. (27. Las itálicas son del autor)

Ansina se niega a ser interpelado por esa llamada del General, colocándose en la posición de un soldado-poeta, cuyo arte sosegaba al héroe. Chagas cita un texto tomado de los poemas atribuidos a Ansina, "La bandera de los pueblos libres" (AA.VV., 1996 : 122-123), del que cita los dos versos finales de la primera estrofa y los dos primeros de la última con una modificación, el verso en el original es "con tu nube y tu rojo en el mar".

Pero el Ansina de Chagas es mucho más que un soldado-poeta. En el sexto fragmento de la novela Artigas se pregunta por la revolución de mayo. En ese momento el discurso de Ansina se intercala :

Columbá, columbá, yum bam bé, balalú, balalú. Abra su corazón, General, y todas preguntas serán respondidas. Permita que el espíritu de Má Ximba "la que nunca duerme" more en su cuerpo. Usted sabe cómo empezó todo. No fue en la Panadería de Vidal, ni en la chacra de la Paraguaya. Fue antes. Mucho antes. (40)

Este pasaje inicia un diálogo entre Artigas y Ansina que atraviesa todo el capítulo. Mientras Artigas se pregunta sobre el significado de la revolución y relata su ingreso en ella desde su deserción de las filas realistas hasta su llegada a Buenos Aires y su contacto con la Junta revolucionaria, Ansina le recuerda que todo empezó en un ritual africano en el que "vio lo que ningún mundele ha visto jamás : el ojo de Ngnangá, el Innombrable" (41). Artigas repasa los hechos y en un momento corta el relato para reconocer que “[t]odo se inició (...) cuando el negro Ansina en cuclillas, con el cuerpo untado en grasa y aceite, abrió la palma de su mano de una cuchillada y brotó de la herida un chorro de sangre espesa que bañó la tierra [y] con los ojos cerrados y la respiración jadeante como su fuera ajeno al dolor, comenzó a cantar sin mover los labios en su antigua lengua (42).

30 Luego Ansina lo desafía : “Mire su destino, que lo llama! Andumba, andumba. ¡Mire al destino! Lo desafié. Y usted, General, vaciló...” (42), Artigas intenta discutir el relato pero Ansina insiste : “y Usted dudó, resopló, maldijo, y al final, miró por la roja cuenca vacía 
del Ngnangá" (42). Artigas continúa su relato cronológico mientras Ansina describe el ritual africano. Finalmente Artigas reconoce : "Mi destino... había visto mi destino" (45).

31 El Ansina de Chagas no es un afrodescendiente aculturado. Este episodio lo muestra además como consejero o líder espiritual, de origen africano, que tuvo un rol protagónico en el origen del Artigas revolucionario y no como un esclavo o sirviente leal. La soledad del General representa un Ansina ya transformado por las polémicas y los dislocamientos de la nación que proponía la novela histórico en los noventas. En La soledad del general Chagas escribe una nueva versión de Ansina, en parte consonante con las propuestas de Mundo Afro en 1996, que vuelve a poner en entredicho el relato oficial, ya desacreditado.

\section{Conclusiones}

Desde la publicación de las novelas Artigas Blues Band (1995) hasta La soledad del General (2001) puede constatarse una importante transformación en la representación de Ansina. Durante el siglo XIX algunas escritores habían intentado, desde una sensibilidad romántica, introducir la figura figura de Ansina como sombra de Artigas, aunque se sabía poco de él. El siglo XX fue, al menos hasta la postdictadura, el momento de la Historia, que no pudo insertar en la narrativa maestra de la nación esta historia-mito. La representación de Ansina encontrará su momento en el marco de un fuerte cuestionamiento a la Historia Nacional y en un proceso de reconfiguración de las narrativas de la nación.

33 La forma dialógica que adopta la dupla Artigas-Ansina en las tres novelas es el indicio más importante de la transformación que opera en la postdictadura. Ansina no aparece como un espectador pasivo del héroe sino como su confidente, su soldado de confianza, su consejero e incluso su guía como plantean Artigas Blues Band o La soledad del General. Luego se introducirán distintos elementos como la posiblidad de que exista como mito pero no como personaje histórico (Bracco), que haya sido un negro vinculado a cultos de origen africano (Chagas) o que sea un fantasma que vaga por Uruguay esperando que sus restos se reúnan con Artigas en el Mausoleo de la Plaza Independencia (Hamed). Todas estas versiones confluyen en una reconfiguración de la forma en que los letrados imaginan a Ansina hacia fines del siglo XX y principios del XXI. Los tres novelistas recogen los distintos materiales historiográficos y los interpretan despreocupados por la verdad de la Historia, concientes de estar escribiendo o re-escribiendo un mito.

34 Ese procedimiento implica una re-interpretación del Ansina oficial que en ningún caso implica una reivindicación política como sí lo es la publicación de sus poemas en 1996. Sin embargo, las tres novelas devuelven unas imagenes de Ansina menos subordinado, creador de payadas y poemas, inmerso en la religiones de origen africano. En definitiva, lo que estos tres textos proponen es un sueño letrado muy distinto al que dio origen al "fiel asistente" de Artigas en el exilio, al que ya no podrá volverse sin tener en cuenta que pertenece a una zona intermedia entre la historia y el mito. 


\section{BIBLIOGRAFÍA}

\section{Bibliografía citada}

Achugar, Hugo. "Paisajes y escenarios de la vida privada, literatura uruguaya entre 1920 y $1990 . "$ Historias de la vida privada en el Uruguay, Tomo III : Individuo y soledades (1920-1990). Montevideo : Taurus, 1998. 208-237.

Basile, Teresa. "Mixed emotions. A propósito de la escritura de Amir Hamed". Katatay. Revista crítica de literatura latnoamericana 11-2 (2005). 52-64.

Brando, Oscar. "La narrativa uruguaya y sus fantasmas (1985-1997)." Papeles de Montevideo 2 (octubre 1997). 10-33.

De María, Isidoro. Vida del Brigadier General D. José Jervacio Artigas, fundador de la nacionalidad oriental. Gualeguaychú : De María y Hermano, 1860.

Draper, Susana. “Cartografías de una ciudad posletrada : la República de Platón (Uruguay, 1993-1995)". Revista Iberoamericana LXIX 202 (enero-marzo 2003). 31-49.

Hammerly Dupuy, Daniel-Hammerly Peverini, Víctor. Artigas en la poesía de América. 2 tomos. Buenos Aires : Noel, 1951.

Pereda Valdés, Ildefonso, El negro en la epopeya artiguista. Montevideo : Barreiro y Ramos, 1964.

Petillo, Mario. El último soldado artiguista. Manuel Antonio Ledesma (Ansina). Montevideo : Imprenta militar, 1939 [1936].

Verani, Hugo J. De la vanguardia a la posmodernidad : narrativa uruguaya (1920-1995). Montevideo : Trilce/Linardi \& Risso, 1996.

Verdesio, Gustavo. "Revisión de la historia oficial en dos novelas « históricas » de la postdictadura uruguaya". Kipus. Revista andina de letras 5 (1996). 41-49.

Verdesio, Gustavo. “ABB: Ten Years After”. Postfacio. Artigas Blues Band. Montevideo: Heditores, 2004. 307-310.

\section{NOTAS}

1. En un artículo de 1996 Gustavo Verdesio presenta esta novela como "la empresa más ambiciosa e innovadora de la serie" (41) en Uruguay. Más adelante menciona la novela Daimón de Abel Posse. La introducción de Artigas Blues Band en la serie uruguaya es, al menos, problemática en la medida en que parece escribirse contra la serie o problematizándola.

2. En dos trabajos anteriores propuse una interpretación más detallada de estas fuentes y de otras no trabajadas aquí, así como un relato de los debates en torno a algunos de los hitos mencionados en este apartado (Gortázar, 2003 : 230-251; y 2006 : 123-132).

3. Hay al menos dos ejemplos en América Latina de "héroes" negros que constrastan con esta representación Ansina-sentado. El primero es el de Carlos Camejo, que pasó a la Historia Nacional de Venezuela como el "Negro Primero" por su lugar en la batalla de Carabobo, uno de los hechos fundantes de la revolución independentista. En el Campo de Carabobo, que recuerda la Batalla de Carabobo (1821), se levantó un Arco en el que aparecía un relieve de Carlos Camejo, uno de los 
tantos negros que murió heroicamente en aquella batalla. El lancero Carlos Camejo está encima de su caballo empuñando una lanza. El segundo caso es el de Brasil con el héroe negro Zumbí, líder de un quilombo que resistió durante dos siglos los diferentes embates imperiales destinados a eliminar esta forma de organización de los pueblos originarios y esclavos cimarrones. Una estatua que lo representa, en el casco histórico de la ciudad de Bahía, lo muestra de pie, semidesnudo y con una lanza, en actitud desafiante.

4. Se trata de : Gonzalo Abella, Nelson Caula, Isabel Izquierdo, Danilo Antón y Armando Miraldi.

5. Se refiere al historiador y ensayista Jorge Pelfort.

6. Publiqué una versión completa de esta entrevista en mi blog: http:// sujetossujetados.wordpress.com/2013/01/09/la-soledad-del-general-entrevista-a-jorge-chagassegunda-parte/

\section{RESÚMENES}

Desde su "aparición" en los primeros textos sobre Artigas, Ansina ha sido un personaje del relato nacional al mismo tiempo histórico y mítico. En ellos fue apenas mencionado como servidor del héroe, un negro fiel asistiendo al amo bueno. Isidoro de María lo creó en 1860 y puso en sus labios la frase "Mi General, yo lo seguiré hasta la muerte". A diferencia de Artigas, la literatura no se ocupó de Ansina. Fueron los historiadores quienes discutieron sobre su identidad durante todo el siglo XX. Recién en el fin de siglo Ansina fue tratado por la ficción. Las novelas Memorias de Ansina (1993) de Diego Bracco, Artigas Blues Band (1994) de Amir Hamed y la nouvelle La soledad del General (2001) de Jorge Chagas fueron posibles en un contexto de transformaciones en la lectura del siglo XIX y en las formas en que la ciudad letrada había interpretado el sueño nacional. En este artículo me propongo analizar cómo estos tres narradores contemporáneos aprovechan la peculiaridad del caso de Ansina y cómo se acercan o se separan de su representación estatal ya consolidada.

Depuis son "apparition" dans les premiers textes autour d'Artigas, Ansina fut un personnage du récit national, un personnage historique et mythique en même temps. Dans ces premiers textes, Ansina fut à peine mentionné comme un serviteur du héros, un noir fidèle à son bon maître. Isidoro de María le créa en 1860 et le fit dire : "Mon Général, moi je vous suivrai jusqu'à la mort". À la différence d'Artigas, Ansina n'intéresse pas les écrivains. Ce sont les historiens qui enquêtent sur l'identité de ce personnage tout au long du XX siècle. Ce n'est qu'à la fin du siècle qu'Ansina suscite l'intérêt des écrivains de fiction. Les romans Mémoires d'Ansina (1993) de Diego Bracco et Artigas Blues Band (1994) d'Amir Hamed et la nouvelle La solitude du Général (2001) de Jorge Chagas deviennent possibles dans un contexte de transformations des manières de lire le XIXe siècle et d'interpréter le rêve national par la ville lettrée. Dans cet article mon objectif est d'analyser comment ces trois narrateurs contemporains se servent des traits particuliers du personnage d'Ansina et comment ils rejoignent ou s'écartent de sa représentation officielle.

Since his "appareance" in the early texts about Artigas, Ansina has been a character of the national narrative historic and mitic simultaneously. He was hardly mencioned as a servant of the hero, a loyal negro attending to his good master. Isidoro de María created him in 1860 and put in his mouth the sentence: "My General, I will comply until death". Unlike Artigas, literature showed little interest in Ansina. It was the historians whom discuss about his identity during the 
XX century. In the recent end of the XX century Ansina was deatl with in fiction. The novels Memorias de Ansina (1993) by Diego Bracco, Artigas Blues Band (1994) by Amir Hamed and the nouvelle La soledad del General (2001) by Jorge Chagas, were possible in a context of transformations in the analysis of the XIX century and in the ways in wich la ciudad letrada had interpreted the national dream. In this article I propose to analize how this three contemporary authors take advantage of Ansina's case distinctive feature and how they were close or far of the consolidated representation of the state.

\section{ÍNDICE}

Mots-clés: fiction narrative uruguayenne, roman historique, afro-descendants, Ansina Palabras claves: narrativa uruguaya, novela histórica, afrodescendientes, Ansina

Keywords: uruguayan narrative, historic novel, Afrodescendants, Ansina

\section{AUTOR}

\section{ALEJANDRO GORTÁZAR}

Universidad de la República, Uruguay 